\title{
Enabling Low-Carbon Development in Poor Countries
}

\author{
Jan Christoph Steckel, Gregor Schwerhoff and Ottmar Edenhofer
}

\begin{abstract}
The challenges associated with achieving sustainable development goals and stabilizing the world's climate cannot be solved without significant efforts by developing and newly-emerging countries. With respect to climate change mitigation, the main challenge for developing countries lies in avoiding future emissions and lock-ins into emission-intensive technologies, rather than reducing today's emissions. While first best policy instruments like carbon prices could prevent increasing carbonization, those policies are often rejected by developing countries out of a concern for negative repercussions on development and long-term growth. In addition, policy environments in developing countries impose particular challenges for regulatory policy aiming to incentivize climate change mitigation and sustainable development. This chapter first discusses how climate policy could potentially interact with sustainable development and economic growth. It focuses, in particular, on the role of industrial sector development. The chapter then continues by discussing how effective policy could be designed, specifically taking developing country circumstances into account.
\end{abstract}

Keywords Developing countries - Climate policy - Sustainable development

J.C. Steckel $(\bowtie) \cdot$ G. Schwerhoff · O. Edenhofer

Mercator Research Institute on Global Commons and Climate Change (MCC), Berlin,

Germany

e-mail: steckel@mcc-berlin.net

J.C. Steckel · O. Edenhofer

Technische Universität Berlin, Berlin, Germany

J.C. Steckel · O. Edenhofer

Potsdam Institute for Climate Impact Research, Potsdam, Germany

(C) The Author(s) 2017

R. Stark et al. (eds.), Sustainable Manufacturing, Sustainable Production,

Life Cycle Engineering and Management, DOI 10.1007/978-3-319-48514-0_3 


\section{Introduction}

Economic development and poverty eradication (as aimed at in the Sustainable Development Goals, SDGs) have in the past gone hand in hand with the large-scale carbonization of countries' energy systems. That is, countries that have been successful in lifting people out of poverty have also dramatically increased their per-capita emissions, hence contributing significantly to climate change. This trend has recently accelerated by a global renaissance of emission-intensive coal. This renewed embrace of coal is mainly driven by countries that currently have low income, but whose economies are growing rapidly. They are investing in cheap and widely available coal to fuel their increasing energy demand and ongoing industrialization (Steckel et al. 2015). Coal-fired power plants that are currently under construction or planned would - if realized - consume one third $\left(240 \mathrm{Gt}_{\text {of }} \mathrm{CO}_{2}\right)$ of the carbon budget still available to achieve a $2{ }^{\circ} \mathrm{C}$ goal (roughly $800 \mathrm{Gt}^{C_{2}}$ ) (Edenhofer et al. 2016). Six developing or newly industrializing countries (China, India, Vietnam, South Africa, Turkey and Indonesia) are responsible for $85 \%$ of ongoing and planned coal investments. In those countries, the relative prices of coal are usually low despite recent cost reductions of low carbon alternatives, including natural gas and renewable energy (Edenhofer et al. 2016).

Against this background, it comes as no surprise that in order to achieve ambitious climate change mitigation targets, more than half of global mitigation (compared to "business as usual" scenarios based on historic correlations between GDP and carbon emissions) will need to take place in today's low and middle-income countries (Jakob and Steckel 2014). In other words, for the Paris Agreement to be successful, these countries cannot replicate the emission- and energy-intense development pathways of the past, but will need to decouple growing GDP and greenhouse gas emissions. Providing energy by means of low carbon technologies, like renewable energy, biomass, nuclear or fossil fuels in combination with carbon-capture and storage (CCS) is thus one important element in the process of detaching emissions from economic growth (IPCC 2014).

Another way of reducing emissions entails reducing energy use, particularly in the manufacturing sectors. Today, technological differences across economic sectors (i.e. value added per energy input in specific sectors, e.g. the automobile sector) the world over can be multiple orders of magnitude, with poor countries usually employing outdated, inefficient technologies (Kim and Kim 2012). Figure 1 shows that sectoral energy intensity levels in rich countries (listed in Annex I to the UNFCCC) are usually much lower than in developing and newly industrializing countries (non-Annex I countries), with some manufacturing sectors showing differences by multiple orders of magnitude.

Ward et al. (2016) show that equalizing existing differences at least to some extent using technology available today, carries potential for global greenhouse gas (GHG) reductions in the energy sector of $10 \mathrm{Gt} \mathrm{CO}_{2}$ or more. This result is obtained considering higher order effects - that is, considering the effect of changes in technology on the entire supply chain (first order effects, in contrast, only take 


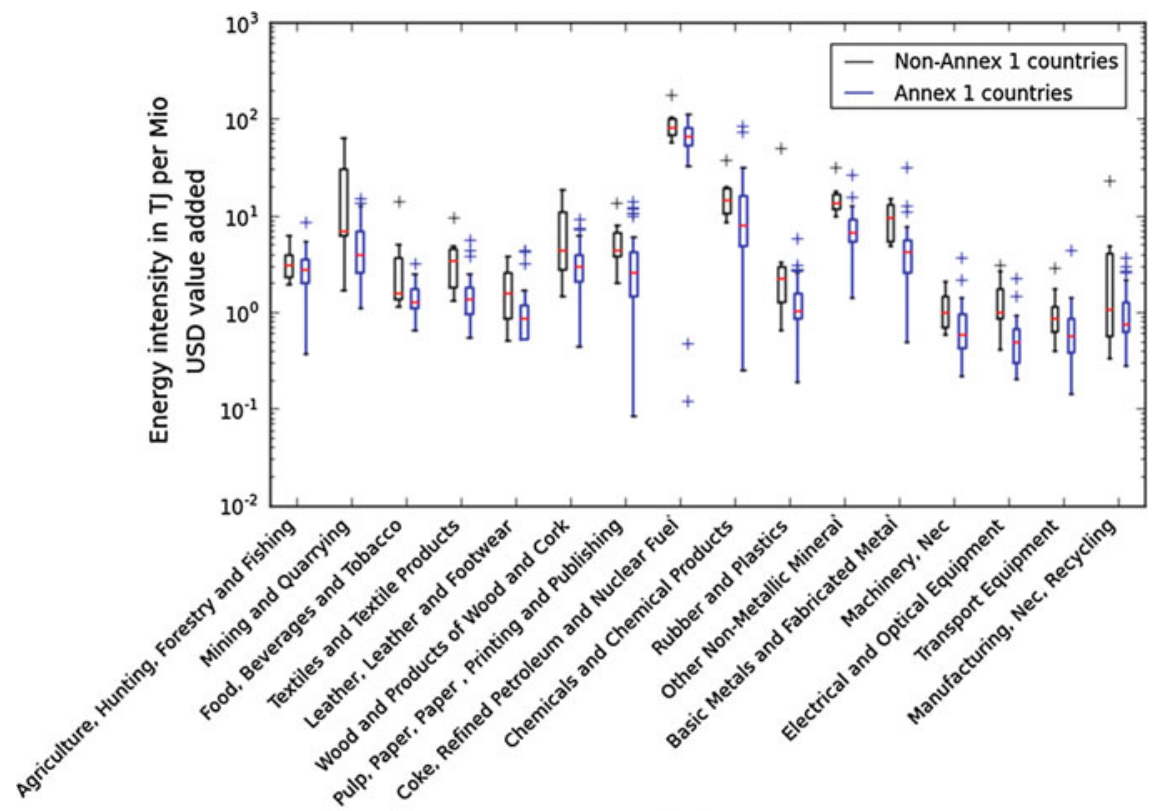

Sectors

Fig. 1 Distribution of energy intensity of industrial sectors across the World Input-Output Database's (WIOD) regions. Boxes represent 25th-75th percentile, red line refers to median. Whiskers in each direction correspond to 1.5 times the interquartile range. Black boxplots represent non-Annex I regions of the UNFCCC, blue boxplots corresponds to Annex I regions. Crosses represent outliers. Source Ward et al. (2016)

direct suppliers into account while multiple layers of the supply chain are ignored). Equalizing existing differences and significantly enhancing energy efficiency levels furthermore likewise play an important role in global mitigation scenarios (IPCC 2014; Luderer et al. 2012).

From an economic point of view, an important question lies in how technological improvements focusing on both the demand side and the investment in low carbon energy systems on the supply side can be incentivized. In this paper we will argue that it is of particular importance to come up with such reward systems that can work in developing country frameworks. Broad agreement among economists holds that a carbon price is the most efficient ("first best") policy instrument. In developing countries, however, carbon prices are hardly ever instituted due to distributive concerns - that is, concerns that the effect of the prices will be distributed unequally amongst the population. A major distributive concern is that carbon prices have a regressive effect, wherein the poor pay proportionally more than the wealthy. Second, there is a concern that carbon prices interfere with economic growth, structural change, involving a shift in importance among different sectors in the economy and industrial development (Jakob and Steckel 2014). While this argument is frequently made by policymakers from developing counties, 
hardly any evidence exists on how exactly structural change and carbon pricing would actually interact.

In this chapter, we will therefore investigate the role of structural change and industrial development on economic growth. Against this background, we will then examine various policy options in developing countries. We will first look into different conceptual possibilities for carbon pricing, including taxes, subsidy removal policies and emissions trading. Second, we will discuss potential barriers specific for developing country environments. We conclude with options for enabling low carbon development in developing countries.

\section{Industrialization, Economic Development and Climate Policy}

In order to properly assess future developments and evaluate the impacts of envisaged climate policies for affected countries, it is crucial to have a clear picture of the role of specific economic sectors in the process of economic growth. It is particularly important to appreciate the role of energy industry sectors for development. Yet, whereas mitigation scenarios as reviewed in the IPCC (2014) display a high level of technological detail in the energy sector, they usually abstract from modelling economic sectors at a fine resolution. For this reason, some key stylized facts on energy use are not well captured by current climate scenarios. For instance, there is a clear correlation of GDP and energy use up to a certain threshold (Steckel et al. 2013; Steinberger and Roberts 2010). Compared to levels that are observed today, additional energy is undoubtedly needed for covering subsistence needs (Rao et al. 2014) as well as provision of basic infrastructure services (Steckel et al. 2013, 2015). Furthermore, the share of the industry sector in countries' energy demand increases dramatically in development processes before it eventually declines again (Schäfer 2005).

Today, most integrated assessment models (IAMs) that are assessed for the IPCC (2014) and thus constitute the backbone of analyses regarding climate change mitigation, rely on economic models which abstract from differences between sectors. These models however do not take any particular income levels or different economic structures explicitly into account. Instead, they assume that the production factors of labour, capital and (in a subset of models) also energy can be substituted with one another at a given cost. Yet this assumption partly contradicts the empirical observations mentioned above. More realistic modelling of economic growth and associated energy use patterns during industrialization could however indeed substantially affect mitigation costs in developing countries.

Early theories of economic growth focused heavily on the role of specific economic sectors and structural changes. Since the works of Hirschman (1958), the structure of an economy - the composition of economic sectors in the overall economy and how they are interlinked - is commonly conceived of as an important 
driver for economic growth. Yet as a result of the analytical intractability of such models, one-sector growth models à la Ramsey (1928) and Solow (1956) have become the workhorse models of both economic theory and several IAMs. Structural change has only recently re-emerged as a central topic (Hansen and Prescott 2002), and has been recognized as one of the main factors of future economic growth, in particular in African countries (McMillan et al. 2014).

This recent work shows that during the development process, the forces which drive structural changes are the changing patterns of demand due to increasing incomes and differences in sectoral (labour) productivities. Early in the development process, economies typically have large agricultural sectors and then develop first the industrial and then the service sector (Herrendorf et al. 2014). Convergence of productivities across countries only takes place in manufacturing sectors, or, in countries that have gone through basic structural changes (Rodrik 2013). Countries going through structural changes first diversify their economies (i.e. building up more complex industrial sectors) and then undertake specializing further once they have reached a certain level of affluence (Imbs and Wacziarg 2003).

Recent economic research has probed more deeply into the processes going on within the three major sectors. These authors regard the economy as a network of interconnected products or sectors. In the process of compiling this information into an aggregate index of economic complexity, it turns out that economic complexity (usually measured in the structure of exports) is predictive of economic growth (Hidalgo et al. 2007; Hidalgo and Hausmann 2009) and can even explain economic growth better than aggregated neo-classical growth models (Hausmann 2007; Hausmann and Hidalgo 2011). Some authors (e.g. Hidalgo and Hausmann 2009) moreover presume increasingly complex export structures to be explainable by means of underlying societal capabilities. Increasing complexity is hence related to the increasingly diverse interplay of ingredients that are of general importance for socio-economic development and growth. Radebach et al. (2016) find a clear community structure of economic sectors by using value-added data. Some sectors occupy a central position in the emerging network, mainly light industry sectors, such as textiles and wood products. These sectors can be deemed to be of particular relevance to economic development, as they allow a transition from an agricultural to an industrialized economy. In line with other results from the literature, this result suggests some sectors of being more important for economic growth than others (Fig. 2).

This observation seems to be especially significant considering that underlying capabilities (such as institutions and human capital) relevant for economic growth and development (e.g. Acemoğlu et al. 2005; Acemoğlu and Robinson 2000) depend on increasing complexity. If building up specific (energy- and carbon intensive) sectors enhances spillovers for general economic development and growth, then this indeed yields decisive consequences for climate policy. It follows then, that failing to go through the process of the industrial stage proves detrimental to an economy aiming at economic growth and sustainable development. Yet more central in the pursuit of sustainable development are the factors of innovation and technological development, or, sustainable manufacturing. 


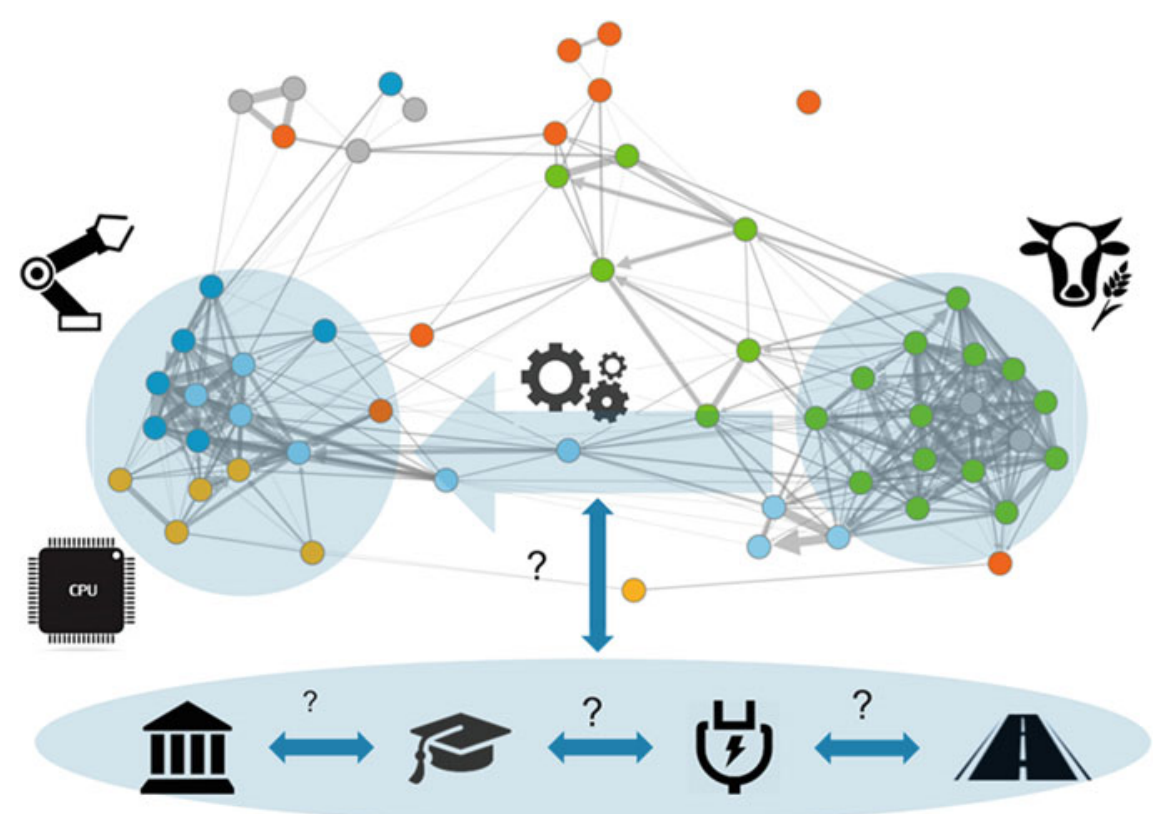

Fig. 2 Stylized representation of the role of manufacturing sectors for structural change and economic development. To the right (green dots), mainly agricultural sectors can be seen, while high-tech (dark blue) and service sectors (yellow) sectors are mainly found on the left hand side. Certain sectors bridge those communities (light manufacturing sectors, light blue), which has given rise to the hypothesis that those sectors are important for building up societal capabilities, including institutions, education, and infrastructure. Adapted from Radebach et al. (2016)

This observation thereby yields important insights for the design of policy instruments in developing countries. Climate policy that discourages investments in manufacturing sectors and decelerates structural change might therefore indeed prove harmful to development - an argument often brought forward by developing countries themselves. For example, from the very onset of the UNFCCC Conference of the Parties in Paris, India's Prime Minister Modi proceeded to highlight, while acknowledging the challenges of climate change for India, that his country will further invest in coal to fuel its energy needs and ensure its right to development.

On that token, the following section will explore the policy options for enhancing low-carbon development in developing countries in more detail. 


\section{Incentivizing Change-Carbon Pricing in a Developing Country Context}

From an economic theory point of view, carbon pricing is the sine qua non of climate policy, a precept broadly agreed upon by economists (see e.g. Acemoglu et al. 2012; Stiglitz 2016; Weitzman 2014). A global price on carbon is generally believed to be a key solution for settling the climate problem, which was recently prominently reiterated by MacKay et al. (2015). Carbon prices ensure that negative implications and damages of emissions - including changes in the climate-are readily transparent and therefore taken into account by market participants, and hence incorporated into investment decisions. Applied to the entire economy, they also ensure that loopholes can be avoided and transaction costs can be kept to a minimum. Other policy instruments, like research subsidies and technology standards, furthermore, have proven quite successful in reducing the energy and carbon intensity of the targeted sectors or products, but at the same time do not prevent increasing emissions in other areas of the economy. This is an effect described as the "rebound effect" (Arvesen et al. 2011; Gillingham et al. 2016)

In this context, it is important to keep in mind that carbon prices can be implemented in a wide variety of ways. While the straightforward method is obviously imposing a tax on carbon (which again can be levied at various points of regulation, up- or downstream), a carbon price can also be applied in the form of a quantity-based instrument, i.e. an emissions trading scheme. Following the logic applied in the Kyoto Protocol, it has long been discussed as a viable means of implementing an international carbon market. In such a trading scheme, the amount of total emissions is capped, while emission allowances are allocated to countries. The allocation is often inspired by an ethical principle and results from specific negotiations between countries, e.g. equal emission rights per capita. An international carbon price would then be established on the grounds of supply and demand for emission certificates. Allocation schemes could be designed in such a way that they favour developing countries insofar as they ensure that they are compensated for the potential incremental costs attached to low-carbon technologies.

While countries are increasingly implementing carbon pricing schemes (in particular OECD countries, World Bank 2015), high fossil fuel subsidies have led to a de facto subsidy for carbon (i.e. a negative carbon price) at the global level (Coady et al. 2015). Foregoing fossil fuel subsidies is hence an important first step in incentivizing climate change mitigation, particularly in developing countries.

While affecting the relative price with carbon prices is appealing conceptually, this process runs up against copious obstacles in developing countries, some of which do not exist in this form in developed countries. First, financing costs are usually higher in developing countries. Typically, interest rates are higher and access to capital is more difficult than in developed countries, as are the political and regulatory risks incurred by investors. Both factors lead to weighted average costs of capital in developing countries being significantly higher than in OECD countries (Schmidt 2014). In this market environment, raising (or implementing) a 
price on carbon would increase energy prices, but not necessarily lead to investment in low-carbon and energy efficient technologies. As those are usually more capital intensive than dirty technologies (Schmidt 2014) a price on carbon can be ineffective in terms of triggering low-carbon investments and hence remains ineffective (Hirth and Steckel, under review). Additional policy instruments designed to alleviate investor risk and buy down technology costs thus might be needed in addition to carbon pricing in order to incentivize low-carbon development.

Second, a range of economic analyses on carbon pricing implicitly presume a liberalized energy market that allows for price signals to be passed through. However, this stands in stark contrast to the (generally) non-liberalized nature of energy markets in many developing countries (Goldblatt 2010; Wisuttisak 2012). Non-liberalized energy markets however indeed grossly impact the effectiveness of carbon pricing. When the government (or one of its agencies) is directly responsible for energy investments, it therefore has to take on payment of the carbon price itself. Unless government agencies, and in particular the energy utility, are made fully responsible for their individual financial performance, the carbon price is unlikely to have any strong incentive effect. This is in particularly true when the government aims to keep energy prices as low as possible, e.g. to prevent negative income effects on poor households or out of the interest in competiveness. In developing countries, where energy utilities are responsible for a large part of total emissions, this situation can mean that total emissions are hardly affected by the carbon price.

Hence, a third obstacle is rooted in distributive concerns. If carbon prices have the desired incentivizing effect, they inevitably cause higher energy prices. Low energy prices, however, are ostensibly considered to be an essential channel for supporting the poor in many countries and are often subsidized for that very reason. What's more, energy prices are considered to be a critical element in the pursuit of the competitiveness of the country's overall economy in the global marketplace. Indeed rising energy prices frequently lead to public protests and societal unrest. Yet balancing distributive issues of rising energy prices is far from impossible. Foregoing fossil fuel subsidies in Indonesia or Iran, for example, have been complemented by transfer schemes favouring poor households (Lindebjerg et al. 2015).

The quality of institutions is also relevant when considering carbon pricing options in developing countries. One frequently proposed model for implementing international carbon prices is an international carbon market, which considers equity issues by means of allowance allocation schemes that favour developing countries. Jakob et al. (2015) emphasize that related transfers could be in the form of resource rents, for example, that yielded negative implications on long-term growth in the past - often referred to as "resource curse". Under such conditions, developing countries might not be able to absorb the carbon rent in a productive way. Low institutional quality and high rates of corruption might also have proven to be pertinent in cases where a pricing instrument was in place related to administrative efforts at monitoring market participants. Even in the EU ETS, some have reported that information asymmetries between regulators and firms have led to reported cases of fraud (Nield and Pereira 2011). 


\section{Conclusion: Climate Policy Solutions for Developing Countries}

Overall, a price on carbon is seen to have the effect of penalizing carbon emissions. To avoid paying this price, firms could reduce emissions per unit of energy by employing low-carbon technology and reducing energy use by improving energy efficiency. However, specific market environments featuring rather low institutional quality, coupled with rather high inequality, high capital costs and regulated energy markets, to mention only a few factors, need all to be taken into careful consideration when crafting the design of policy instruments. Most importantly, it needs to be acknowledged that distributional concerns, both regarding the poorest parts of countries' populations as well as decelerated economic growth (i.e. slower convergence to developed countries' income levels), likewise figure into the equation in a huge way for policy makers in developing countries.

Given this background, Jakob et al. (2016) propose using revenues from carbon pricing to finance infrastructure investment. In many countries, the revenues which a government can collect from taxing $\mathrm{CO}_{2}$, can then be utilized to finance SDGs, e.g. access to water, sanitation or electricity. In the case of Nigeria, Dorband (2016) shows that a carbon tax deployed in this way turns out to be largely progressive, and hence can alleviate distributional concerns.

In addition, it will be necessary to institute de-risk measures for investments in low-carbon technologies. While one possibility could be to implement subsidies in addition to carbon prices, it may well be useful to offer additional securities to companies that aim to invest in developing countries. Those securities today are often granted to fossil fuels (Coady et al. 2015).

Moreover, carbon taxes can be levied downstream, for example, at the sale of the final good to the consumer, or upstream, where a fossil fuel is extracted or imported. Given issues with institutional quality, it seems that levying carbon taxes upstream is the most useful mechanism for introducing a carbon tax in developing countries. Even when markets remain regulated in this way, fossil fuel costs increase. This would also be relevant for investment decisions taken by governments themselves.

An open question however remains with regards to carbon taxes possibly ushering in a decelerating force on industrial development. As literature shows possible positive spillovers from a more complex economy, it might therefore be necessary to come up with industrial policy to complement climate policy in order to alleviate negative effects on growth and development. Future research will be needed to better appreciate the precise relationship between industrial development and climate policy.

Finally, the UNFCCC demands common but differentiated responsibility and burden sharing, implying support from developed for developing countries both for climate change adaptation and mitigation. Based on those fundamental principles, international climate finance (e.g. by the Green Climate Fund) is supposed to support the low-carbon transformation of developing countries. While international 
climate finance is slowly under way, it is still rather unclear how exactly it will be disbursed. It will be an interesting question for future climate negotiations to tackle how to redesign international climate finance to support structural transformations towards low-carbon development and economic leapfrogging in pursuit of climate change mitigation.

\section{References}

Acemoglu, Daron, Philippe Aghion, Leonardo Bursztyn, and David Hemous. 2012. The environment and directed technical change. American Economic Review 102(1): 131-166. doi:10.1257/aer.102.1.131.

Acemoğlu, Daron, Simon Johnson, and James A. Robinson. 2005. Institutions as a fundamental cause of long-run growth. In Handbook of economic growth, ed. Philippe Aghion and Steven Durlauf, 1:385-472. Amsterdam: Elsevier.

Acemoğlu, Daron, and James A. Robinson. 2000. Political losers as a barrier to economic development. American Economic Review 90(2): 126-130.

Arvesen, Anders, Ryan M. Bright, and Edgar G. Hertwich. 2011. Considering only first-order effects? How simplifications lead to unrealistic technology optimism in climate change mitigation. Energy Policy 39: 7448-7454.

Coady, David, Ian Parry, Louis Sears, and Shang Baoping. 2015. How large are global energy subsidies? WP/15/105. IMF Working Paper. Washington D.C.: International Monetary Fund. https://www.imf.org/external/pubs/ft/wp/2015/wp15105.pdf.

Dorband, Ira. 2016. Using revenues from carbon pricing to close infrastructure access gapsdistributional impacts on Nigerian households. Master thesis, FU Berlin.

Edenhofer, Ottmar, Jan Christoph Steckel, Michael Jakob, and Christoph Bertram. 2016. How cheap coal threatens the paris agreement. MCC Working Paper.

Gillingham, Kenneth, David Rapson, and Gernot Wagner. 2016. The rebound effect and energy efficiency policy. Review of Environmental Economics and Policy 10(1): 68-88. doi:10.1093/ reep/rev017.

Goldblatt, Michael. 2010. Comparison of emissions trading and carbon taxation in South Africa. Climate Policy 10(5): 511-526.

Hansen, G., and E. Prescott. 2002. Malthus to Solow. American Economic Review 92: 1205-1217.

Hausmann, Ricardo. 2007. What you export matters. Journal of Economic Growth 1: 1-25.

Hausmann, Ricardo, and César Hidalgo. 2011. The network structure of economic output. Journal of Economic Growth 16: 309-342. doi:10.1007/s10997-011-9071-4.

Herrendorf, Berthold, Richard Rogerson, and Ákos Valentinyi. 2014. Growth and structural transformation. In Handbook of economic growth, ed. Philippe Aghion and Steven Durlauf, 2:855-941. Amsterdam: Elsevier.

Hidalgo, César A., and Ricardo Hausmann. 2009. The building blocks of economic complexity. Proceedings of the National Academy of Sciences 106(26): 10570-10575. doi:10.1073/pnas. 0900943106.

Hidalgo, Cesar A., Bailey Klinger, Albert-L. Barabási, and Ricardo Hausmann. 2007. The product space conditions the development of nations. Science 317(5837): 482-487. doi:10.1126/ science. 1144581 .

Hirschman, A.O. 1958. The strategy of economic development. Yale studies in economics 10. New Haven, CT, USA: Yale University Press.

Imbs, Jean, and Romain Wacziarg. 2003. Stages of diversification. American Economic Review 93 (1): 63-86. doi:10.1257/000282803321455160. 
IPCC. 2014. Climate change 2014: mitigation of climate change. Contribution of Working Group III to the Fifth Assessment Report of the Intergovernmental Panel on Climate Change, ed. Ottmar Edenhofer, Ramón Pichs-Madruga, Youba Sokona, E. Farahani, S. Kadner, K. Seyboth, A. Adler, et al. Cambridge, United Kingdom and New York, NY, USA: Cambridge University Press. http://mitigation2014.org.

Jakob, Michael, Claudine Chen, Sabine Fuss, Annika Marxen, and Ottmar Edenhofer. 2015. Development incentives for fossil fuel subsidy reform. Nature Climate Change 5(8): 709-712.

Jakob, Michael, Claudine Chen, Sabine Fuss, Annika Marxen, Narasimha D. Rao, and Ottmar Edenhofer. 2016. Carbon pricing revenues could close infrastructure access gaps. World Development. doi:10.1016/j.worlddev.2016.03.001.

Jakob, Michael, and Jan Christoph Steckel. 2014. How climate change mitigation could harm development in poor countries. WIREs Climate Change 5: 161-168. doi:10.1002/wcc.260.

Kim, Kyunam, and Yeonbae Kim. 2012. International comparision of industrial $\mathrm{CO}_{2}$ emission trends and the energy efficiency paradox utilizing production-based decomposition. Energy Economics 34(5): 1724-1741.

Lindebjerg, Erik S., Wei Peng, and Stephen Yeboah. 2015. Do policies for phasing out fossil fuel subsidies deliver what they promise? Working Paper 2015-1. UNRISD Working Papers. Geneva, Switzerland: United Nations Research Institute for Social Development (UNRISD). http://www.unrisd.org/80256B3C005BCCF9/httpNetITFramePDF?ReadFormandparentunid= 170D2DA8A96A5352C1257DC40050C975andparentdoctype $=$ paperandnetitpath $=80256-$ B3C005BCCF9/(httpAuxPages)/170D2DA8A96A5352C1257DC40050C975/\$file/Lindebjerg\%20et\%20al.pdf.

Luderer, Gunnar, Valentina Bosetti, Michael Jakob, Jan Christoph Steckel, Henri Waisman, and Ottmar Edenhofer. 2012. The economics of decarbonizing the energy system-results and insights from the RECIPE model intercomparison. Climatic Change 114(1): 9-37.

MacKay, David J.C., Peter Cramton, Axel Ockenfels, and Steven Stoft. 2015. Price carbon-I will if you will. Nature 526(7573): 315-316. doi:10.1038/526315a.

McMillan, Margaret, Dani Rodrik, and Íñigo Verduzco-Gallo. 2014. Globalization, structural change, and productivity growth with an update on Africa. World Development 63: 11-32. doi:10.1016/j.worlddev.2013.10.012.

Nield, K., and R. Pereira. 2011. Fraud on the European Union emissions trading scheme: Effects, vulnerabilities and regulatory reform. European Energy and Environmental Law Review 20(6): 255-289.

Radebach, Alexander, Jan Christoph Steckel, and Hauke Ward. 2016. Patterns of sectoral structural change-empirical evidence from similarity networks. http://ssrn.com/abstract= 2771653.

Ramsey, F.P. 1928. A mathematical theory of saving. The Economic Journal 38(152): 543-559.

Rao, Narasimha D., Keywan Riahi, and Arnulf Grubler. 2014. Climate impacts of poverty eradication. Nature Climate Change 4(9): 749-751. doi:10.1038/nclimate2340.

Rodrik, Dani. 2013. Unconditional convergence in manufacturing. Quarterly Journal of Economics 128(1): 165-204. doi:10.1093/qje/qjs047.

Schäfer, Andreas. 2005. Structural change in energy use. Energy Policy 33: 429-437.

Schmidt, Tobias S. 2014. Low-Carbon investment risks and de-risking. Nature Climate Change 4 (4): 237-239.

Solow, R. 1956. A Contribution to the Theory of Economic Growth. The Quarterly Journal of Economics 70: 65-94.

Steckel, Jan Christoph, Robert J. Brecha, Michael Jakob, Jessica Strefler, and Gunner Luderer. 2013. Development without energy? Assessing future scenarios of energy consumption in developing countries. Ecological Economics 90: 53-67. doi:10.1016/j.ecolecon.2013.02.006.

Steckel, Jan Christoph, Ottmar Edenhofer, and Michael Jakob. 2015. Drivers for the renaissance of coal. Proceedings of the National Academy of Sciences 112(29): E3775-E3781.

Steinberger, Julia K., and J. Timmons Roberts. 2010. From constraint to sufficiency: The decoupling of energy and carbon for human needs, 1975-2005. Ecological Economics 70: 425-433. 
Stiglitz, Joseph E. 2016. How to restore equitable and sustainable economic growth in the United States †. American Economic Review 106(5): 43-47. doi:10.1257/aer.p20161006.

Ward, Hauke, Alexander Radebach, Ingmar Vierhaus, Armin Fügenschuh, and Jan Christoph Steckel. 2016. Reducing global $\mathrm{CO}_{2}$ emissions with the technologies we have. MCC Working Paper.

Weitzman, Martin L. 2014. Can negotiating a uniform carbon price help to internalize the global warming externality? Journal of the Association of Environmental and Resource Economists 1 (1/2): 29-49. doi:10.1086/676039.

Wisuttisak, Pornchai. 2012. Regulation and competition issues in Thai electricity sector. Energy Policy 44: 185-198.

World Bank. 2015. State and Trends of Carbon Pricing 2015. Washington, DC: World Bank.

Open Access This chapter is licensed under the terms of the Creative Commons Attribution 4.0 International License (http://creativecommons.org/licenses/by/4.0/), which permits use, sharing, adaptation, distribution and reproduction in any medium or format, as long as you give appropriate credit to the original author(s) and the source, provide a link to the Creative Commons license and indicate if changes were made.

The images or other third party material in this chapter are included in the book's Creative Commons license, unless indicated otherwise in a credit line to the material. If material is not included in the book's Creative Commons license and your intended use is not permitted by statutory regulation or exceeds the permitted use, you will need to obtain permission directly from the copyright holder.

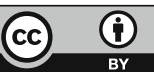

